\title{
CAPILLARY RESISTANCE IN RHEUMATOID ARTHRITIS
}

\author{
BY \\ J. L. POTTER AND F. W. WIGZELL \\ Rheumatic Unit, Northern General Hospital, Edinburgh
}

(RECEIVED FOR PUBLICATION MARCH 6, 1957)

For more than 50 years, tests of "capillary resistance" have been used to measure the facility with which petechiae may be produced experimentally, mainly with a view to detecting latent purpuric tendencies. Hare and Miller (1951) listed the many different methods which have been evolved, and assessed the merits and demerits of techniques in general use. "Pressure" tests, such as the snake venom test, have been used more extensively than any other method and can be defined in two broad categories.

In "positive pressure" tests, the arm is constricted by a sphygmomanometer, the number of petechiae appearing in response to venous engorgement of the forearm serving as an index of capillary resistance.

"Negative pressure" tests require apparatus consisting of a vacuum pump, a manometer, and a suction cup which can be applied to the skin. The pressure of air in the system is reduced to a predetermined level for a period, and the number of petechiae thus produced in the underlying skin, in relation to the magnitude and duration of the negative pressure applied, is used as a measure of capillary resistance.

While it is unlikely that all the different modifications of these tests measure the same biological properties, suction or "negative pressure" techniques have an advantage over other procedures in that tests can be repeated in an individual at intervals of a few hours and can be used to measure, for example, the influence of substances the administration of which may produce rapid and transient changes in capillary resistance.

It has been customary to regard the expressions "capillary resistance" and "capillary fragility" as interchangeable, but it should be noted that "increased resistance" is equivalent to "diminished fragility" and vice versa.

Although these tests were originally introduced to facilitate the study of haemorrhagic diseases, the results of investigations in this field have been somewhat conflicting. In a review of the subject of capillary resistance tests in scurvy, Munro, Lazarus, and Bell (1947) concluded that most investigators had failed to demonstrate a significant relationship between capillary strength and ascorbic acid reserves assessed by chemical methods. Nevertheless, Scarborough (1953) observed reasonably good correlation between depletion of ascorbic acid and the level of capillary resistance in otherwise normal subjects. In other haemorrhagic disorders, capillary resistance appeared to be unrelated to the bleeding time, the coagulation time, or the number of thrombocytes (Hare and Miller, 1951). In thrombocytopenic purpura, however, Elliott (1938), Elliott and Whipple (1940), and Robson (1949) found evidence of a consistent relationship between capillary resistance and the "bleeding tendency".

It is possible that tests of capillary resistance are a measure of haemostatic mechanisms other than those primarily involved in haemorrhagic disorders, and this conception might explain the frequently anomalous results of such tests in patients with purpura. The available evidence indicates that the maintenance of normal levels of resistance may depend upon the integrity of the perivascular connective tissue; histological studies of petechiae induced by suction applied to normal skin have revealed fragmentation of elastic fibres in the vicinity of haemorrhages without evidence of damage to capillary endothelium (Peck, Rosenthal, and Erf, 1937). The low capillary resistance found in premature, but otherwise normal, infants has been attributed to under-development of the connective tissues around cutaneous blood vessels (Hare and Miller, 1951). From experimental evidence, Zweifach (1955) concluded that increased capillary fragility may be a consequence of a disturbance in the structure of the connective tissue sheath of small cutaneous vessels. The foregoing therefore suggests that tests of capillary resistance 
may be a measure of some property of connective tissues anatomically related to small cutaneous vessels.

Factors other than disease may influence capillary resistance; data originating from many sources reveal a consistent inverse relationship between capillary resistance and increasing age, and show that it tends to be lower in women than in men (Hare and Miller, 1951). In recent years it has been established that there is a relationship between capillary resistance and adrenocortical activity (Robson and Duthie, 1950, 1952; Kramár, 1953; Kramár and Simay-Kramár, 1953; Kramár, Meyers, and Peetz, 1954; Kramár, Wilhelmj, Meyers, Milani, Gunderson, Shuput, Racher, and Mahoney, 1954).

Robson and Duthie (1952) observed that capillary resistance could be increased in patients with rheumatoid arthritis by the administration of cortisone or corticotrophin, and in some instances the increase coincided with the temporary clinical improvement produced by the hormones.

A survey of the literature gave little additional information about the level of capillary resistance in rheumatic diseases. Wiemer (1931) included "polyarthritis" in a list of diseases associated with increased capillary fragility. Brown and Wasson (1941) observed that resistance was frequently subnormal during the course of rheumatic fever in children. Warter, Drezner, and Horoschak (1946) found evidence of increased capillary fragility in twenty patients with rheumatoid arthritis, but Heikinheimo (1953) found resistance to be greater than normal in the majority of a large number of rheumatic patients. The results reported in this last paper will be discussed later.

In view of the possibility that capillary resistance may be a measure of some property of connective tissue, and in view of the evidence to indicate that the level of resistance could be increased by administration of corticotrophin or cortisone, it was considered that more detailed information about capillary resistance in rheumatoid arthritis would be of interest.

\section{Material and Methods}

The report is an account of two independent surveys of capillary resistance, each conducted by one observer. In each survey, capillary resistance was measured in a group of patients suffering from rheumatoid arthritis, and in a comparable number of control subjects. Because capillary resistance was measured in the second survey by a method which differed from that used in the first, the results obtained in the two surveys were analysed separately.

Capillary resistance was measured in 549 individuals, of whom 220 were patients suffering from rheumatoid arthritis, this diagnosis having been established on the basis of unequivocal clinical, radiological, and haematological evidence. Patients were excluded from the surveys if the arthritis was complicated by intercurrent illness.

Control readings were obtained from normal members of the staff of the hospital, from a large number of patients in the Neurological, Orthopaedic, and Respiratory Diseases Units of the hospital, and from a number of individuals attending the various out-patient clinics. Additional information about the composition of these groups is given in Tables I and II.

TABLE I

NUMBERS OF INDIVIDUALS IN THE MAIN GROUPS IN EACH SURVEY

\begin{tabular}{|c|c|c|c|c|c|c|}
\hline \multicolumn{2}{|l|}{ Survey } & .. & \multicolumn{2}{|c|}{ First } & \multicolumn{2}{|c|}{ Second } \\
\hline Sex & . & . & Male & Female & Male & Female \\
\hline \multirow{3}{*}{ Group .. } & Normal .. & . & 19 & 31 & 16 & 16 \\
\hline & Miscellaneous & . & 62 & 58 & 53 & 74 \\
\hline & $\begin{array}{l}\text { Rheumatoid } \\
\text { Arthritis }\end{array}$ & . & 54 & 71 & 41 & 54 \\
\hline Total &.. & .. & \multicolumn{2}{|c|}{295} & \multicolumn{2}{|c|}{254} \\
\hline
\end{tabular}

TABLE II

COMPOSITION OF THE GROUPS OF MISCELLANEOUS DISEASES

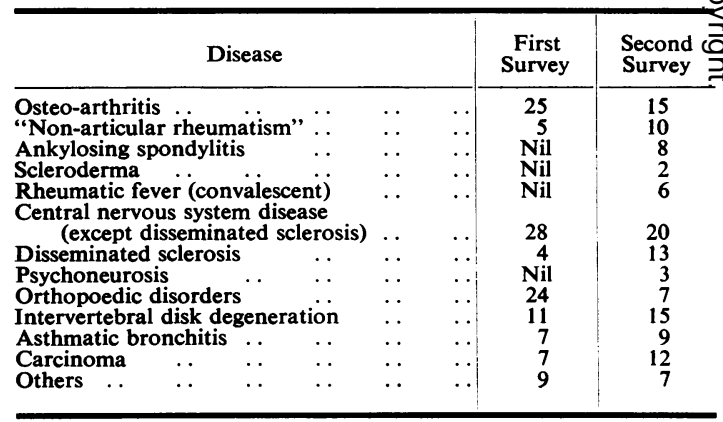

No attempt was made to standardize the conditions of the tests in relation to factors such as environmental temperature or time of day. Tests were made in the controls concurrently with those in rheumatoid arthritis, over a period of 3 years, and it is unlikely that these factors could have had a systematic influence upon the results obtained.

The negative pressure apparatus used in the investigation (Fig. $1 a$ and $b$, opposite) was similar in principle to that described by Robson and Duthie (1950).

First Survey.-Capillary resistance was measured by a method described by Scarborough (1941). The negative pressure which produced between one and ten petechiae was found by a process of trial and error. In every case, an initial trial was made at a negative pressure of 200 $\mathrm{mm} . \mathrm{Hg}$; further trials were made in adjacent areas of 


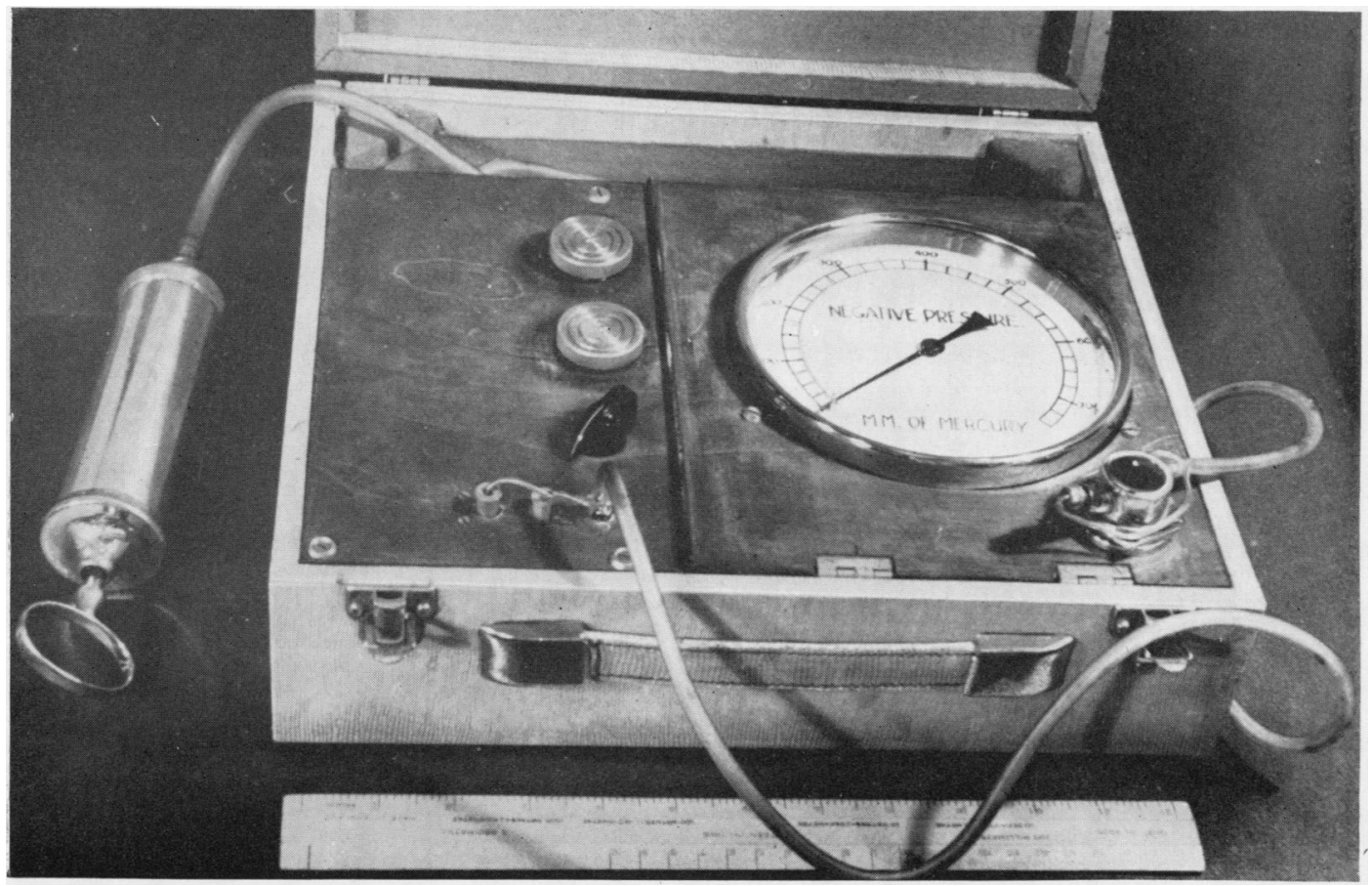

Fig. (1a). Negative pressure apparatus.

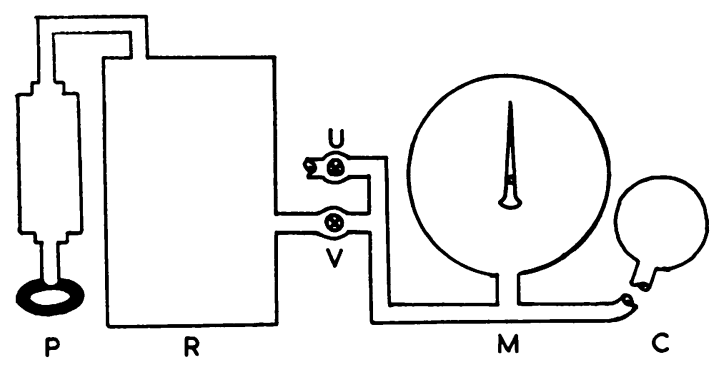

Fig. (1b) Diagram of pneumatic system.

$\mathbf{P}=$ pump $\quad \mathbf{R}=$ reservoir; $\mathbf{U}=$ release valve; $\mathbf{V}=$ suction valve $\mathbf{M}=$ manometer; $\mathbf{C}=$ cup.

skin with pressures $50 \mathrm{~mm}$. $\mathrm{Hg}$ above or below this according to the number of petechiae, if any, which appeared in response to the first. Suction was applied for 30 -sec. periods by means of a cup $23 \mathrm{~mm}$. in diameter. The skin was inspected for petechiae without a lens under illumination from a standard endoscope bulb. The result recorded in each subject was the mean of measurements obtained at three levels on the volar aspect of the forearm, the first being situated exactly midway between the wrist and the elbow, and the second and third immediately above and below.

In order to facilitate analysis of the results, a single figure representing the resistance in $\mathrm{mm}$. $\mathrm{Hg}$ was derived by means of an approximation based upon the assumption that a $50-\mathrm{mm}$. increment of negative pressure tends to produce, on an average, ten additional petechiae (Robson and Duthie, 1950).

\section{For example:}

If suction for $30 \mathrm{sec}$. at $200 \mathrm{~mm}$. Hg produced three petechiae, the "critical petechial pressure" was $200-\left(\frac{3}{10} \times 50 \mathrm{~mm}\right.$. $\left.\mathrm{Hg}\right)=185 \mathrm{~mm}$. $\mathrm{Hg}$.

The true relationship between numbers of petechiae and pressure follows a logarithmic pattern, but this linear adjustment, confined as it was to the results of tests producing ten petechiae or fewer, did not introduce a serious error.

Second Survey.-The method used was derived from the procedure followed by Schweppe, Lindberg, and Barker (1948). The test consisted of applying a series of negative pressures at $30-\mathrm{sec}$. intervals, starting at $50 \mathrm{~mm}$. $\mathrm{Hg}$ and increasing by intervals of $50 \mathrm{~mm}$. $\mathrm{Hg}$, all to the same area of skin, by means of a suction cup $23 \mathrm{~mm}$. in diameter. After each application of negative pressure, the petechiae present in the test area were counted, the test being concluded when the number exceeded forty. To increase the accuracy of counting the large number of petechiae produced at higher negative pressures, the skin was blanched by firm pressure from a watch glass inscribed with a circle $23 \mathrm{~mm}$. in diameter, subdivided into squares (Fig. 2, overleaf). Petechiae were unselected in terms of size or of distribution within this circular area, 
all semi-permanent red spots being included in the counts. With this method it was possible to follow exactly the same procedure at virtually the same area of skin in every subject. Capillary resistance tends to be lower in the lateral elbow region than in any other part of the forearm, and this area was therefore selected for the test in order to minimize the number of increments of negative pressure required to produce forty or more petechiae. The area was located by aligning the outer rim of the cup with the biceps tendon and with the lowermost crease at the elbow.

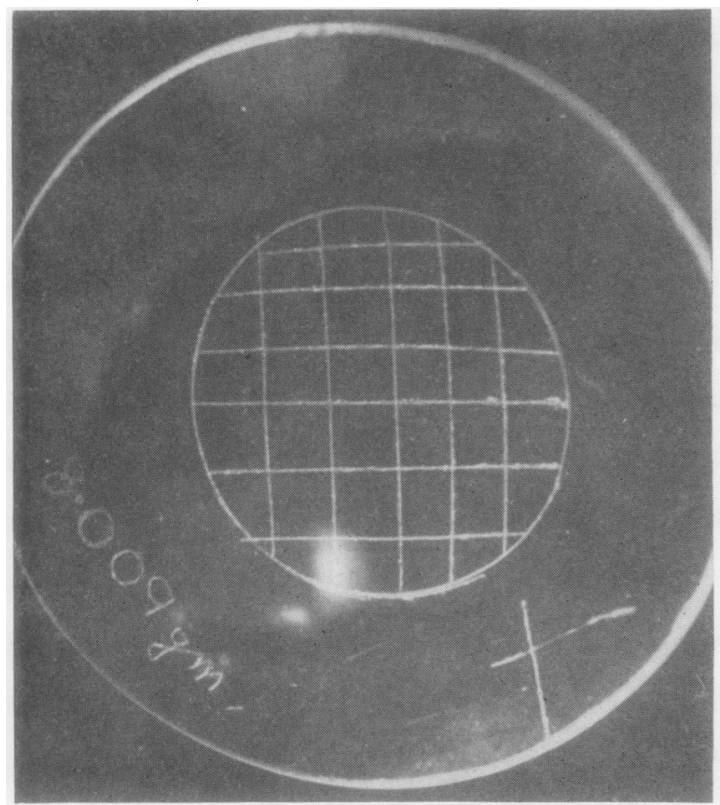

Fig. 2.-Watch glass for blanching skin to facilitate enumeration of petechiae. Central area $23 \mathrm{~mm}$. in diameter.

The results of this test can be recorded as a curve relating numbers of petechiae to negative pressure. Such curves are not amenable to analysis by simple statistical methods, and for this purpose a single figure was derived, by interpolation, for the negative pressure corresponding to ten petechiae ("C.P.10", Fig. 3). Interpolation was made on the straight line joining the observed numbers of petechiae immediately above and below ten. A preliminary analysis showed very close correlation between the pressures relative to five, ten, and forty petechiae, and it is therefore unlikely that qualitatively different information would have been obtained by interpolating at numbers other than ten within this range.

A more precise method for deriving a single figure for resistance would consist of interpolation upon the regression line calculated from all the petechial counts observed in each test. However, the much simpler procedure adopted was adequate for the purpose of determining the mean resistance and its variance in different groups of individuals.

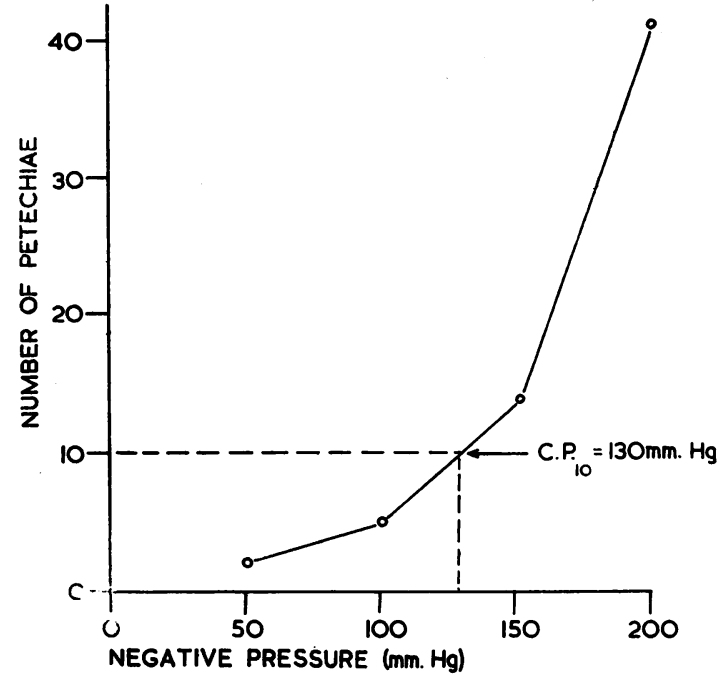

Fig. 3.-Typical "curve" of petechiae plotted against negative pressure.

\section{Results}

The mean capillary resistance of the group of patients with rheumatoid arthritis was significantly lower than that of the miscellaneous or norma $\vec{c}$ group $(p<0.05)$. The results of the two surveys are shown in Fig. 4 (opposite), which also indicates the extent to which the various groups differed from each other in age and sex distribution.

It has been reported that capillary resistance falls with increasing age (Munro and others, 1947) and that it tends to be lower in women than in men (Hare and Miller, 1951). Consequently, it was necessary to estimate the influence of these factors upon the results obtained in this investigation.

Appropriate methods of analysis revealed a consistent inverse relationship between age and resistance which can be represented by the linear regression equations:

First Survey:

C.R. (in mm. $\mathrm{Hg}$ ) $=283-1.49 x$ (age in years). $(r=-0 \cdot 330, n=293, P<0.001)$

\section{Second Survey:}

C.P. $\cdot 10$ (in $\mathrm{mm} . \mathrm{Hg}$ ) $=270-1 \cdot 33 \times$ (age in years) $(r=-0 \cdot 330, n=252, P<0 \cdot 001)$

The regression coefficients in these equations overestimate slightly the rate at which resistance diminishes with increasing age. This error was revealed by estimating regression of resistance upon 0 age within each of the main subgroups, and com- $\mathbb{D}$ bining the coefficients by the " $z$ " transformation ? (Fisher, 1954). 


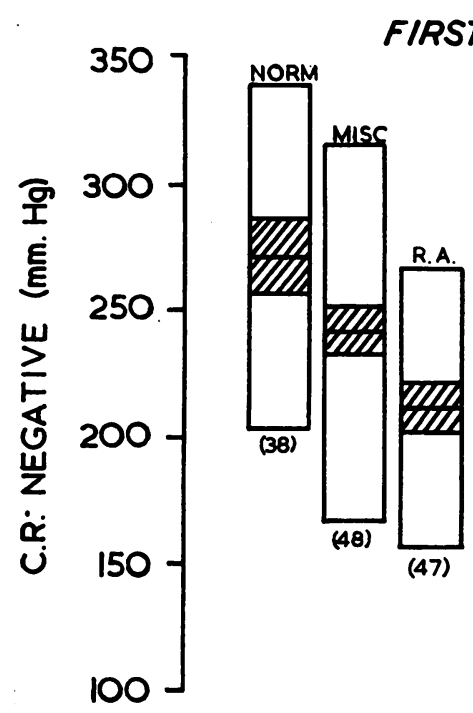

\section{SURVEY}

\section{FIRST SURVEY}
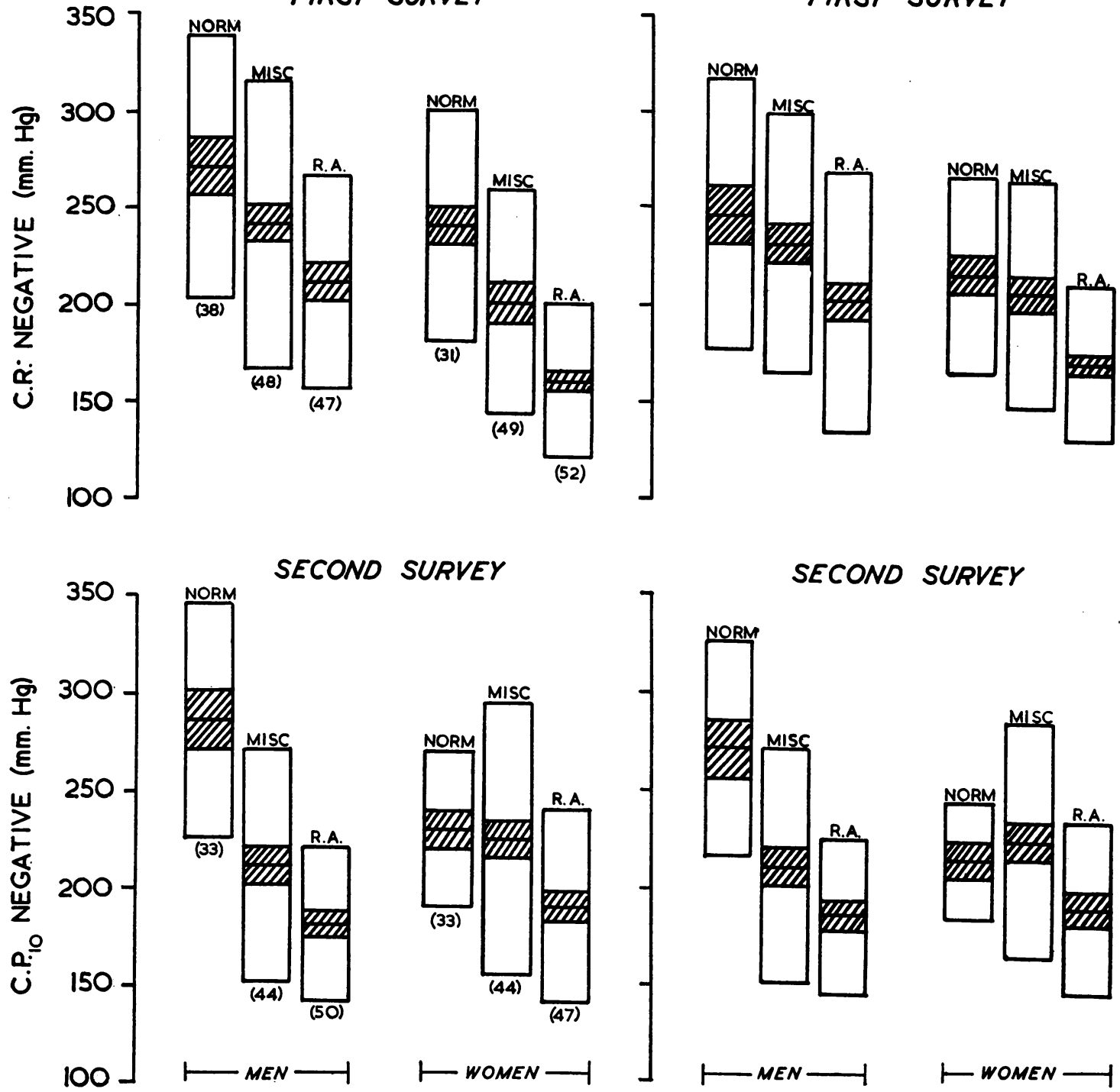

Fig. 4.-Means of capillary resistance \pm standard errors (hatched) and standard deviations (blank). (Numbers in brackets are mean ages.)

Fig. 5.-Means of capillary resistance \pm standard errors (hatched) and standard deviations (blank). Means and deviations adjusted to values expected at mean of ages of all individuals tested in each survey.

The difference between this "combined" coefficient and the regression estimated from the observations taken as one class represents the bias introduced by the incidental association in the rheumatoid arthritis group of greater age and lower resistance.

The "biased" estimates of regression were used to adjust the means and standard deviations of resistance of each of the subgroups, the figures being standardized at the mean of the ages of all individuals in the respective surveys. The overall effect of the adjustment can be seen by comparing Fig. 5 with Fig. 4 . Despite the fact that the probable effect of the bias is to underestimate the difference between the resistance of the rheumatoid arthritis group and that of the other two groups, the standardized figures confirm that, irrespective 
of the influence of age, the mean resistance of the R.A. group was significantly lower than that of the controls $(p<0.05)$.

Fig. 5 shows that the results of this investigation support the view that capillary resistance tends to be lower in women than in men; it is also apparent that inequalities of sex distribution have not, for this reason, contributed to producing fallacious differences between the means of the various subgroups. This difference between the sexes was more obvious in the first survey than in the second.

Other factors which might conceivably have affected the results were physical activity and treatment, in that patients suffering from rheumatoid arthritis tend to be more limited in their activities, and to consume more salicylates, than otherwise comparable individuals. While there is nothing in the literature to suggest that either of these factors might significantly influence capillary resistance, it was possible to obtain confirmatory evidence for this negative conclusion from the results of this investigation. There was no significant difference between the means of resistance of otherwise comparable groups of patients classed as either ambulant or recumbent, according to the phase predominating at the time of the test. Moreover, in patients suffering from rheumatoid arthritis, there was no correlation between capillary resistance and daily intake of salicylates such as might have been expected had the drug in fact affected resistance sufficiently to make the mean resistance of the R.A. group fallaciously low.

Lastly, by using the correlation coefficient as a measure of association, the results obtained indicated that in rheumatoid arthritis capillary resistance was unrelated either to the duration of the disease, or to its activity measured by the erythrocyte sedimentation rate.

Before discussing the possible implications of these findings, it is necessary to study the data from the miscellaneous group of patients in greater detail, particularly in view of the fact that the mean resistance in these groups was lower than those observed in the normal groups (Fig. 5). While this difference was not nearly so great as that between the mean of the R.A. group and of the other two groups, it has been reported that subnormal capillary resistance may be found in a variety of diseases. Brown (1947) compiled a list of these diseases which included scarlet fever, measles, rheumatic fever, allergy, asthma, bronchopneumonia, peptic ulcer, colitis, hypertension, myxoedema, diabetes mellitus, and, of course, purpura. Recently Shulman and his colleagues found abnormally low capillary resistance in a large group of patients with disseminated sclerosis (Shulman, Alexander, Ehrentheil, and Gross, 1950).

In the second survey, capillary resistance was subnormal in 35 of the 127 patients in the miscellaneous group, the "normal range" being the mean of the normal group, plus and minus the standard deviation (187 to $291 \mathrm{~mm}$. $\mathrm{Hg}$ at age 44 ). The incidence of this abnormality of approximately 28 per cent. in the miscellaneous group is not significantly greater than in the normal group $(0.7>P>0.5)$. However, tabulation of the data from these 35 patients indicates that certain diseases were associated with low capillary resistance (Table III). It is emphasized that these groups are small, but the low mean of resistance in asthmatic bronchitis and the low levels observed in some patients with disseminated sclerosis are in agreement with the results obtained by other investigators. In the group of respiratory disorders it was impossible in many instances to decide whether the primary disease was asthma or bronchitis, hence the two conditions have been classed together as "asthmatic bronchitis".

\section{TABLE III}

INCIDENCE OF “SUBNORMAL” LEVELS OF CAPILLARY RESISTANCE IN THE MISCELLANEOUS GROUP OF THE ज SECOND SURVEY

Readings standardized at age 44

\begin{tabular}{|c|c|c|c|c|}
\hline \multirow{2}{*}{\multicolumn{2}{|c|}{ Disease }} & \multicolumn{2}{|c|}{$\begin{array}{l}\text { Incidence of "Sub- } \\
\text { normal" Resistance } \\
\text { in Each Group }\end{array}$} & \multirow{2}{*}{$\begin{array}{l}\text { Mean of } \\
\text { Resistance } \\
\text { of Group } \\
\text { (mm. Hg) }\end{array}$} \\
\hline & & No. & $\begin{array}{c}\text { Per- } \\
\text { centage }\end{array}$ & \\
\hline $\begin{array}{l}\text { Intervertebral disk degen } \\
\text { Asthmatic bronchitis } \\
\text { Disseminated sclerosis } \\
\text { Carcinoma } \\
\text { Ankylosing spondylitis } \\
\text { Others* . . . . }\end{array}$ & 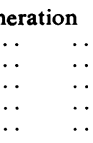 & $\begin{array}{r}10 \\
5 \\
5 \\
4 \\
2 \\
9\end{array}$ & $\begin{array}{l}66 \\
56 \\
40 \\
33 \\
25 \\
13\end{array}$ & $\begin{array}{l}184 \\
176 \\
219 \\
227 \\
221 \\
232\end{array}$ \\
\hline
\end{tabular}

* Including one example of each of the following: Fractured femur, quadriceps tear, meniscectomy, tuberculous sacro-ileitis, "nonarticular rheumatism", dystrophia myotonica, epilepsy, tuberculous meningitis, and encephalomyelitis (all convalescent).

Subnormal capillary resistance was found in ten of the fifteen patients with disk degeneration, an incidence significantly greater than that found in the remainder of the miscellaneous group $\left(\chi^{2}=11 \cdot 18\right.$, $P<0 \cdot 01)$. Further examination of the results from these fifteen patients revealed that in many the resistance was extremely low, and the very low readings in the twelve patients in whom there was no obvious predisposing cause for disk degeneration, such as achondroplasia or severe scoliosis, were distributed closely round a mean level below that of the patients with rheumatoid arthritis. 
In eight patients with ankylosing spondylitis the mean resistance fell within the normal range.

\section{Discussion}

From the evidence presented, it may be concluded that the mean capillary resistance, measured by the methods described, was lower in a group of patients suffering from rheumatoid arthritis than in otherwise comparable groups of individuals. The results of appropriate tests indicated that the difference was statistically significant and was not attributable to any recognizable source of bias.

Although these groups of patients were not strictly random samples of the "rheumatoid" and "non-rheumatoid" populations, the results are sufficiently consistent to suggest that they do in fact reflect a general tendency for capillary resistance to be subnormal in patients with rheumatoid arthritis. Observations reported by Wiemer (1931) and by Warter and others (1946) lend some support to this conclusion, but it should be noted that Wiemer did not clearly define the nature of the "polyarthritis" mentioned in his paper, and that Warter and his colleagues used a positive pressure test for their study of capillary resistance in rheumatoid arthritis.

From a study of over 250 individuals, Heikinheimo (1953) concluded that capillary resistance tended to be higher than normal in patients with rheumatoid arthritis. The validity of many of his observations is possibly vitiated by his own statement that "The highest value of those (C.R. values) obtained in the same examination has usually been taken into account, since climatic or other disturbing factors may possibly have contributed to the lowness of the other values". Statistical tests give meaningless results when applied to data obtained by such a process of selection. In any case, Heikinheimo measured resistance in the supra- and infra-clavicular region, and as yet no evidence is available to show that the characteristics of these areas are necessarily identical with those of other areas, such as the forearm.

It is emphasized that the subnormal resistance observed in rheumatoid arthritis in these two surveys was in fact the mean of the results obtained in a large number of patients, and that many individual readings in this group lay within normal limits. Capillary resistance is characterized by having a relatively large coefficient of variation of 25 to 35 per cent., and this may arise in several ways. At the extremes, the test is either an accurate measure of some biological property which varies over a wide range, or else it is an inaccurate measure of a relatively stable property. While approximately 30 per cent. of the total variance in the two surveys may be attributable to regression with age, to differences between sexes, and to differences between disease groups, the residual variation is substantial.

Reference has already been made to the unreliability of capillary resistance as a measure of the "haemostatic mechanisms" involved in purpuric disorders, and there is in fact no evidence of a specific bleeding tendency in rheumatoid arthritis. It is possible that negative pressure tests measure some property of perivascular connective tissue, and the low resistance observed in rheumatoid arthritis may be evidence of a widespread disorder of connective tissue.

The absence of correlation between resistance and the activity of the disease or its duration would suggest that the disorder reflected by low capillary resistance is a "soil" factor, rather than a secondary manifestation of the disease. The fact that subnormal values have been observed in other conditions, such as rheumatic fever, asthma, and disseminated sclerosis, and possibly in the presence of degeneration of the intervertebral disks, indicates that the changes in the tissues leading to a fall in capillary resistance are in no way specific. The association of low resistance with degeneration of the intervertebral disks may be evidence of accelerated aging of connective tissue, as resistance becomes lower with increasing age in normal people.

The significance of the low capillary resistance in rheumatoid arthritis is unknown, and its possible bearing on the development of the disease is obscure. Much more detailed knowledge of the constitution and metabolism of connective tissue is required. The rise in capillary resistance which follows the administration of corticotrophin or cortisone and which accompanies the reduction in the signs of inflammation in patients with rheumatoid arthritis, is of great interest, but is unlikely to have any bearing on the pathogenesis of the disease, since it is possible to increase capillary resistance in normal subjects also by administration of these hormones.

\section{Summary}

(1) An account is given of two surveys of capillary resistance in normal individuals, hospital patients suffering from rheumatoid arthritis, and patients with other diseases.

(2) The mean resistance in the groups of patients with rheumatoid arthritis was significantly lower than that observed in the control groups. This difference was not attributable to the recognized influence upon capillary resistance of factors such as age and sex.

(3) The fundamental significance of this abnor- 
mality, which is not specific to rheumatoid arthritis, is discussed in terms of other published data on capillary resistance. It is concluded that the low levels of resistance found in rheumatoid arthritis may be related to the widespread disorder of connective tissue which is regarded as a feature of the disease.

We wish to thank the members of the medical and nursing staff of the Northern General Hospital for permitting access to patients under their care in the Neurological, Orthopaedic, and Respiratory Diseases Units.

For assistance in dealing with the statistical aspect of the investigation we are greatly indebted to Dr. P. E. Brown, formerly of the Department of Public Health and Social Medicine, University of Edinburgh. During the course of the investigation and in the preparation of this report, Dr. J. J. R. Duthie has been an unfailing source of encouragement and constructive criticism, for which we are most grateful.

Throughout the period when this work was done, the Rheumatic Unit was in receipt of grants from the Nuffield Foundation, the Medical Research Council, and Boots Pure Drug Company Limited.

\section{REFERENCES}

Brown, E. E. (1947). Amer. Heart J., 34, 241

Brown. 18 . (1941). J. Pediat., 18, 328

Elliott, R. H. E. (1938). J. Amer. med. Ass., 110, 1177

Elliott, R. H. E. (1938). J. Amer. med. Ass., 110, 1177. 489.

Fisher, R. A. (1954). "Statistical Methods for Research Workers" 12th ed., pp. 197-204. Oliver and Boyd, Edinburgh and London.

Hare, F. W., and Miller, A. J. (1951). A.M.A. Arch. Derm. Syph., $64,449$.

Heikinheimo, R. (1953). Ann. Med. intern. Fenn., 42, Suppl. 15

Kramár, J. (1953). Amer. J. Physiol., 175, 69.

-, Meyers, V. W., and Peetz, D. J. (1954). J. Lab. clin. Med., 43, 395 .

— and Simay-Kramár, M. (1953). Endocrinology, 52, 453. Wilhelmj, C. M., Meyers, V. W., Milani, D. P., Gunderson, D. E. Shuput, D., Racher, E. M., and Mahoney, P. S. (1954). Amer. J. Physiol., 178, 486.

Munro, H. N., Lazarus, S., and Bell, G. H. (1947). Nutr. Abstr. Rev., 17, 291.

Peck, S. M., Rosenthal, N., and Erf, L. (1937). Arch. Derm. Syph. (Chicago), 35, 831.

Robson, H. N. (1949). Quart. J. Med., 42, (n.s. 18), 279.

and Duthie, J. J. R. (1950). Brit. med. J., 2, 971.

- (1952). Ibid., 1, 994

Scarborough, H. (1941). Edinb. med. J., 48, 555.

(1953). M.R.C. Report No. 280.
Shulman, M. H. Alexander, L., Ehrentheil, O, F, and Gross, R (1950). J. Neuropath., 9, 420.

Schweppe, J., Lindberg, H. A., and Barker, M. H. (1948). Amer. Heart J., 35, 393.

Warter, P. J., Drezner, H. L., and Horoschak, S. (1946). J. med. Soc. N.J., 43, 228.

Wiemer, P. (1931). Z. ges. exp. Med., 78, 229.

Zweifach, B. W. (1955). Ann. N.Y. Acad. Sci., 61, 670.

\section{Résistance capillaire dans l'arthrite rhumatismale RÉSUMÉ}

(1) On présente un compte-rendu de deux enquêtes concernant la résistance capillaire chez des sujets normaux, des malades hospitalisés atteints d'arthrite rhumatismale et des sujets atteints d'autres maladies.

(2) La résistance moyenne dans les groupes de malades atteints d'arthrite rhumatismale était significativement inférieure à celle observée dans les groupes témoins. Cette différence n'était pas imputable à l'influence des facteurs qu'on sait capables d'affecter la résistance capillaire, tels que l'âge et le sexe.

(3) La signification fondamentale de cette anomalie, qui n'est pas spécifique de l'arthrite rhumatismale, est discutée à la lumière d'autres données publiées sur la résistance capillaire. On conclut que les chiffres bas de résistance capillaire, trouvés dans l'arthrite rhumatismale, seraient liés aux désordres étendus des tissus conjonctifs, ce qu'on regarde comme un des caractères de la maladie.

\section{Resistencia capilar en la artritis reumatoide SUMARIO}

(1) Se relatan dos investigaciones de la resistencia capilar en sujetos normales, en enfermos hospitalizados con artritis reumatoide $y$ en sujetos con otras enfermedades.

(2) La resistencia media en los grupos de enfermos con artritis reumatoide fué significativamente inferior a la observada en los grupos testigos. Esta diferencia no fué imputable a factores conocidos que afectan la resistencia capilar como la edad y el sexo.

(3) Se discute el significado fundamental de esta anomalia, que no es específica de artritis reumatoide, en la luz de otros datos publicados sobre la resistencia capilar. Se concluye que las cifras bajas de resistencia capilar, observadas en la artritis reumatoide, pudieran relacionarse con las alteraciones extensas de los tejidos conjuntivos, considerándose esto como un rasgo de la enfermedad. 